\title{
"Se ha de armar siempre a los fuertes contra los débiles". La crítica de Nietzsche a la democracia
}

\section{"The strong must always be armed against the weak". Nietzsche's Critique of Democracy}

\author{
Scarlett Marton ${ }^{1}$ \\ Universidad de São Paulo (Brasil) \\ ORCID: https://orcid.org/0000-0002-6869-3371
}

Recibido: 16-01-2021

Aceptado: 01-02-2021

\section{Resumen}

Se trata de discutir las críticas que este pensador francamente antidemocrático hace a la democracia, cuestionando y evaluando los argumentos que emplea para ello. Primero se pretende aclarar sus reflexiones sobre la modernidad y la decadencia, para comprender las razones que lo llevan a asociar el movimiento democrático con las llamadas "ideas modernas". Después, centrando el análisis en la idea de igualdad, se examinan las consecuencias de su posición a favor del aristocratismo.

Palabras-clave: Nietzsche, democracia, modernidad, décadence, aristocratismo.

\footnotetext{
${ }^{1}$ (smarton@usp.br) Profesora Titular de Filosofía Contemporánea de la USP. Fundadora del Grupo de Estudos Nietzsche (GEN), de la revista Cadernos Nietzsche y editora de la colección "Sendas \& Veredas". Forma parte del consejo científico del grupo HyperNietzsche, del anuario Nietzsche-Studien y de la serie "Monographien und Texte zur Nietzsche-Forschung". Es autora de diez libros dedicados a Nietzsche. Entre los más recientes: Nietzsche, filosofo da suspeita (Casa da Palabra, Rio de Janeiro; casa de Saber, Sâo Paulo, 2010), Nietzsche, seus leitores e suas leituras (Barcarolla, Sâo Paulo, 2010), Nietzsche e a arte de decifrar enigmas (Loyola, Sâo Paulo, 2014), Nietzsche y "la nueva concepción del mundo" (Córdoba, Argentina, Brujas, 2017).
} 


\begin{abstract}
It is about discussing the criticisms that this frankly undemocratic thinker makes to democracy, questioning and evaluating the arguments he uses for it. First, it is intended to clarify his reflections on modernity and decadence, to understand the reasons that lead him to associate the democratic movement with the so-called "modern ideas". Then, focusing the analysis on the idea of equality, the consequences of his position in favor of aristocratism are examined.
\end{abstract}

Key-words: Nietzsche, Democracy, Modernity, Decadence, Aristocratism.

Durante mucho tiempo, los comentaristas descuidaron por lo general los aspectos políticos del pensamiento nietzscheano ${ }^{2}$. Entre los diversos factores que contribuyeron a ello, hay que señalar la necesidad que se impuso entonces de descalificar los diferentes usos y apropiaciones políticas de las ideas de Nietzsche.

Sin embargo, en las últimas décadas han comenzado a surgir trabajos que se preguntan si existe o no una dimensión política en los textos del filósofo; se ubican sobre todo en el contexto de los estudios publicados en lengua inglesa ${ }^{3}$. Mientras que algunos autores no aceptan que el pensamiento nietzscheano pueda presentar una dimensión política stricto sensu $u^{4}$, otros sostienen, por el contrario, que Nietzsche es un pensador político ${ }^{5}$. Adoptando esta última perspectiva, hay

\footnotetext{
${ }^{2}$ Una de las raras excepciones, durante el período comprendido entre el final de la Segunda Guerra Mundial y 1985, es el libro de S. Goyard-Fabre, Nietzsche et la question politique, Paris: Sirey, 1977.

3 Cf. A. Mc Intyre, The Sovereignty of Joy. Nietzsche's Vision of Grand Politics, Toronto: University Press, 1997; D. Owen, Nietzsche, Politics and Modernity. A Critical of Liberal Reason, Londres: Thousand Oaks, 1995; K. Ansell-Pearson, An Introduction to Nietzsche as Political Thinker, Cambridge: University Press, 1994; P. Bergmann, Nietzsche. The "Last Anti-Political German", Bloomington: Indiana University Press, 1987. Cf. también el libro en alemán de H. Ottmann, Philosophie und Politik bei Nietzsche, Berlin: de Gruyter, 1987.

${ }^{4}$ Cf. por ejemplo T. H. Brobjer, "The Absence of Political Ideals in Nietzsche's Writings", en Nietzsche-Studien 27 (1998), pp. 300-318. El autor se dedica a examinar los textos en los que Nietzsche se ocupa de las Leyes de Manu. En su opinión, estos pasajes del Crepúsculo de los Ídolos (Los "mejoradores" de la humanidad $\S 3$ ) y del Anticristo $(\S 56, \S 57, \S 58)$ constituyen los enunciados "políticos" más problemáticos de Nietzsche; no expresan un ideal político, pero forman parte de la crítica del filósofo al cristianismo y la modernidad. Así, Brobjer apoya la tesis de que la política, la moral y la religión están íntimamente ligadas en el pensamiento nietzscheano. Véase en otra dirección P. Sedgwick, "Violence, Economy and Temporality. Plotting the Political Terrain of On the Genealogy of Morality", en Nietzsche-Studien 34 (2005), pp. 163-185. A partir del análisis de ciertos pasajes de la Genealogía de la Moral, el autor intenta establecer una relación entre las consideraciones de Nietzsche sobre la economía y su concepción de la "gran política".

5 En su artículo "Virtuosos of Contempt': An Investigation of Nietzsche's Political Philosophy Through Certain Platonic Political Ideas”, en Nietzsche-Studien 21 (1992), pp. 184-210, a partir de una comparación entre la filosofía nietzscheana y el pensamiento platónico, Mc Intyre defiende la idea de que Nietzsche es un pensador político. En primer lugar, porque el autor de Zaratustra tendría en mente una transformación cultural fundamental, que requeriría la creación de una jerarquía espiritual y una nueva tabla de valores; luego, porque no se podría confundir la "gran política" con el poder
} 
estudiosos postestructuralistas que intentan poner la concepción nietzscheana del agon al servicio de una nueva comprensión de la democracia ${ }^{6}$ y hay quienes argumentan que de ninguna manera podría tomarse en esa dirección ${ }^{7}$. Portando la huella del tiempo y del espacio en que surgen, ciertos textos se dejan llevar a controversias localizadas 8 ; limitándose a adoptar un punto de vista específico, a menudo responden a intereses puntuales ${ }^{9}$.

A partir del examen del corpus nietzscheano en su conjunto, no dudamos en afirmar que las reflexiones del filósofo sobre cuestiones relacionadas con el poder no son suficientes para constituir una teoría política acabada. Nietzsche no se presenta como un teórico del poder en el sentido estricto del término; tampoco quiere ser un analista político. Sin embargo, no por eso deja de reflexionar sobre temas centrales de la filosofía política ni sobre los problemas candentes de su tiempo. Son frecuentes las ocasiones en las que se detiene a examinar la relación entre el individuo y el Estado, y también en las que se dedica a analizar el Segundo Reich y a Bismarck, el sufragio universal y los ejércitos nacionales, los partidos políticos y la situación de la prensa, la desaparición de naciones y la unificación de Europa. Aunque atento a este orden de cuestiones, no les confiere un estatuto propio, no las encuadra en un dominio particular del conocimiento ni las aborda con una metodología específica. Por el contrario, en su obra la política aparece estrechamente vinculada a la moral y a la religión; mejor dicho: moral, política y religión constituyen un punto nodal en su pensamiento. Íntimamente ligadas, forman parte de un campo de investigación más amplio: son objeto de la crítica de los valores. Desde este punto de vista es desde el que Nietzsche considera acontecimientos históricos, corrientes de ideas, sistemas de gobierno; y es también en estos términos en los que afronta la democracia, el socialismo, el anarquismo; es dentro de estos parámetros como los evalúa.

político del Estado. Ahora bien, concebida de esta manera, la política no constituiría, en mi opinión, una dimensión particular del pensamiento nietzscheano; ella integra la investigación sobre los valores.

${ }^{6}$ Cf. A. D. Schrift, "Nietzsche for Democracy?", en Nietzsche-Studien 29 (2000), pp. 220-232; L. J. Hatab, A Nietzschean Defense of Democracy. An Experiment in Postmodern Politics, Chicago: Open Court, 1995; B. Honig, Political Theory and the Displacement of Politics, Ithaca: Cornell University Press, 1993; W. Connoly, Political Theory and Modernity, Oxford: University Press, 1989; M. Warren, Nietzsche and Political Thought, Cambridge, MIT Press, 1988.

7 Cf. C. D. Acampora, "Demos Agonists Redux. Reflections of the Streit of Political Antagonism", en Nietzsche-Studien 32 (2003), pp. 374-390; F. Appel, Nietzsche contra Democracy, Ithaca: Cornell University Press, 1999; D. Conway, Nietzsche and the Political, Londres: Routledge, 1997.

${ }^{8}$ Cf. por ejemplo D. Dombowsky, "A Response to Thomas H. Brobjer's 'The Absence of Political Ideals in Nietzsche's Writings"”, en Nietzsche-Studien 30 (2001), pp. 387-393 y Th. H. Brobjer, "Nietzsche as Political Thinker. A Response to D. Dombowsky", en Nietzsche-Studien 30 (2001), pp. 394-396; D. Dombowsky, "A Response to Alan D. Schrift's 'Nietzsche for Democracy?", en Nietzsche-Studien 31 (2002), pp. 278-290 y A. D. Schrift, "Response to Don Dombowsky", en Nietzsche-Studien 31 (2002), pp. 291-297.

9 En cuanto a los estudios publicados recientemente sobre Nietzsche como pensador político, véase G. Luque, "Informe bibliográfico: Nietzsche y la política", in Estudios Nietzsche 15 (2015), pp. 157-163; Hermann Siemens, "Nietzsche's Political Philosophy : A Review of Recent Literature", en Nietzsche-Studien 30 (2001), pp. 508-526. 
El propósito que perseguimos aquí consiste en discutir la crítica que este pensador francamente antidemocrático hace a la democracia. A fin de comprender las razones que le llevan a asociar el movimiento democrático a las llamadas "ideas modernas", intentaremos, primero, aclarar sus reflexiones sobre la modernidad y la décadence. Luego, centrando el análisis en la idea de igualdad, pretendemos examinar las consecuencias de su posición a favor del aristocratismo. Finalmente, esperamos cuestionar y valorar los argumentos a los que recurre para luchar contra la democracia.

$* * *$

En sus escritos, Nietzsche advierte reiteradas veces que "se ha de armar siempre a los fuertes contra los débiles"10. Además del número, los débiles tendrían a su favor la maestría en el arte del engaño. Dando mayor importancia al instinto de conservación que al de la vida, desde muy temprano desarrollaron los talentos para el engaño; para evitar enfrentamientos que no habrían podido soportar, pronto aprendieron a actuar de manera insidiosa. Con eso, esperaban conservar su existencia a cualquier precio. A juicio del filósofo, esta estrategia forma parte del surgimiento de las "ideas modernas". Tanto es así que escribe en un fragmento póstumo:

Cristianismo, revolución, abolición de la esclavitud, igualdad de derechos, filantropía, amor a la paz, justicia, verdad: todas estas grandes palabras sólo tienen valor en la lucha, como estandartes: no como realidades, sino como palabras fastuosas para algo completamente diferente ( $¡$ e incluso opuesto!) ${ }^{11}$.

Analizar las "ideas modernas" es una de las tareas que Nietzsche se propone en gran parte de sus escritos. Al presentar una visión retrospectiva de su obra en Ecce Homo, refiriéndose a Más allá del Bien y del Mal, afirma: "El ojo, mal acostumbrado por una enorme presión a mirar a lo lejos [...] se ve obligado aquí a percibir con agudeza lo más cercano, la época, lo que nos rodea" 12 . Pero al sacar a la luz la perspectiva que pretende adoptar, también deja claro el objeto que elige para el análisis: "Este libro (1886) es, en todo lo esencial, una crítica de la modernidad, sin excluir de ello las ciencias modernas, las artes modernas, incluso la política moderna, dando a la vez indicaciones para un tipo antitético, que es lo menos moderno posible, un tipo aristocrático,

${ }^{10}$ Cf. Fragmento póstumo 14 [123] primavera de 1888, KSA 13.304: "Por extraño que suene: se ha de armar siempre a los fuertes contra los débiles; a los felices contra los desgraciados: a los sanos contra los depravados y los lastrados con taras hereditarias". Usamos la edición de las Obras completas (4 vols.) y los Fragmentos póstumos (4 vols.) dirigida por Diego Sánchez Meca, Madrid: Editorial Tecnos, 2006-2016.

${ }^{11}$ Fragmento póstumo 11 [135] noviembre de 1887-marzo de 1888, KSA 13.62.

12 Ecce Homo, "Más allá del Bien y del Mal", § 2, KSA 6.351. 
que dice sí"13. Esclareciendo el objetivo que tiene en mente en Más allá del bien y del mal, Nietzsche dilucida al mismo tiempo la amplitud del objeto de su crítica. Por su criba hará pasar el sentido histórico y la objetividad científica, la música wagneriana y la literatura francesa en general, la emancipación femenina y la igualdad de derechos.

Para intentar comprender las razones que llevaron a Nietzsche a asociar a la democracia con las "ideas modernas", consideremos sus reflexiones sobre la modernidad. Múltiples y complejas, engloban el diálogo y la crítica de los filósofos modernos; una tradición y una ruptura con la filosofía moderna en cuanto un todo; una comprensión y un posicionamiento en relación a las llamadas "ideas modernas". Sin embargo, en el epílogo de El caso Wagner, Nietzsche parece explicitar con mayor claridad lo que entiende por modernidad $^{14}$. Partiendo de las ideas de vida ascendente y descendente, subraya la necesidad de antagonismos. En el dominio de los llamados valores morales, éstos se harían sentir en la relación entre la moral de señores y la moral de esclavos. Pero, por no tenerlos en cuenta, Wagner coqueteó con la moral de los nobles y, al mismo tiempo, dio voz a la doctrina cristiana. Pasando entonces al wagnerismo, el filósofo concluye su análisis: "El ser humano moderno representa, biológicamente, una contradicción en los valores, está sentado entre dos sillas, simultáneamente dice si y dice no"15. Sin poder contar con una fuerza organizadora capaz de establecer jerarquías, la modernidad es décadent.

Es cierto que el término "décadence" sólo aparece en 1888 en los textos de Nietzsche publicados o destinados a publicación ${ }^{16}$. En sus últimos escritos comenzó a utilizar el término para designar una idea muy precisa, en la que

\footnotetext{
${ }^{13}$ Ecce Homo, "Más allá del Bien y del Mal", § 2, KSA 6.350.

${ }^{14}$ Sobre las diferentes concepciones de la modernidad, cf. E. Behler, Ironie und literarische Moderne, Paderborn: Ferdinand Schöningh, 1997. Refiriéndose a la conciencia de la modernidad literaria, Behler sostiene, que, en el paso del siglo XVIII al XIX, pocos años después de la Revolución Francesa, un grupo de jóvenes escritores, entre ellos los hermanos Schlegel, Novalis, Tieck, Wackenroder, Schleiermacher, sentó las bases de una literatura moderna. Argumenta que, mientras que en la filosofía la conciencia de la modernidad estaría ligada a la idea de progreso científico, introducida en el siglo XVII por Bacon y Descartes, en el dominio estético será necesario esperar más de ciento cincuenta años para que las concepciones de progreso, perfectibilidad y la modernidad se impongan. Con el inicio del romanticismo, a finales del siglo XVIII y principios del XIX, la poesía, la literatura y las artes fueran consideradas por primera vez en un proceso de constante progresión o renovación. Mientras que la filosofía tendría por marco Kant y la política, la Revolución Francesa, la literatura tomaría por marco el romanticismo. En cada caso, se trataba de superar el antiguo orden en favor de una visión moderna. Por otro lado, conviene señalar que si, en El Caso Wagner, Nietzsche explica con mayor claridad lo que entiende por modernidad, en el transcurso de su obra parece cambiar de posición en relación al romanticismo. Sobre la relación que él establece con el romanticismo alemán, véase el excelente libro de E. Behler, Frühromantik, Berlin: de Gruyter, 1992; véase también, entre otros, A. Del Caro, Nietzsche contra Nietzsche, Louisiana: State University Press, 1989.

${ }^{15}$ El Caso Wagner, "Epílogo", KSA 6.52. Con respecto a este pasaje, véase S. Kofman, "Nietzsche et Wagner. Comment la musique devient bonne pour les cochons", en Furor 23 (Mai 1992), pp. 3-28.

${ }_{16}$ Cabe recordar que el término "décadence" aparece inicialmente en Fragmento póstumo 16 [5] Otoño 1883, KSA 10.497: "Profunda esterilidad del siglo XIX. [...] Aparentemente todo es decadencia".
} 
hay resonancias de las concepciones de Paul Bourget ${ }^{17}$. En los Ensayos de psicología contemporánea, Bourget se dedica a analizar el movimiento de desintegración que cree presenciar en la literatura francesa contemporánea. Al caracterizarlo, afirma:

Un estilo de decadencia es aquel en que la unidad del libro se descompone para dejar lugar a la independencia de la página, en que la página se descompone para dejar lugar a la independencia de la frase y la frase para dejar lugar a la independencia de la palabra ${ }^{18}$.

Son estas líneas, presentes en las cuatro páginas tituladas "Teoría de la decadencia", las que contribuyen en gran medida a hacer famosa su obra ${ }^{19}$. También dejan huella en el pensamento nietzscheano ${ }^{20}$.

Como Paul Bourget, Nietzsche ve la décadence como un movimiento de disgregación ${ }^{21}$. En sus escritos, se aplica a diagnosticarla dondequiera que aparezca. En El Anticristo escribe: "Yo afirmo que todos los valores en los que la humanidad sintetiza el tiempo supremo de lo deseable, son valores de

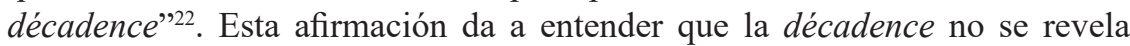

${ }^{17}$ Nietzsche tenía en su biblioteca el libro Nouveaux essais de psychologie contemporaine, Paris: A. Lemerre, 1887, de Bourget, y otras dos obras del mismo autor: André Cornelis, Paris: A. Lemerre, 1887, y Études et portraits, Paris: A. Lemerre, 1888. Cf. G. Campioni et al. (eds.), Nietzsches persönliche Bibliothek, Berlin: de Gruyter, 2003, pp. 147-149.

18 P. Bourget, Baudelaire y otros estudios críticos, trad. de S. Sánchez, Córdoba: Ediciones de Copista, 2008, pp. 91-92; en francés, P. Bourget, Essais de psychologie contemporaine. Études littéraires, Paris: Gallimard, 1993, p. 14.

19 Estas páginas están, como sabemos, en la primera parte del libro, titulada "Baudelaire". Sobre la recepción de Baudelaire por Nietzsche, véase K. Pestalozzi, "Nietzsches Baudelaire-Rezeption", en Nietzsche-Studien 7 (1978), pp. 158-178. El autor trata de las relaciones entre Nietzsche, Wagner, Bourget y Baudelaire, dejando claro que el filósofo no dejó de subrayar la proximidad que creía que existía entre Baudelaire y Wagner. De hecho, en el Fragmento póstumo 34 [166] abril-junio de 1885, KSA 11.476, llega a ver Baudelaire como "una especie de R[ichard] W[agner] sin música".

${ }^{20}$ En El Caso Wagner $\S 7$, KSA 6.27, Nietzsche retoma las frases de Bourget prácticamente en los mismos términos: “QQué es lo que caracteriza a toda décadence literaria? El hecho de que la vida ya no habita en el todo. La palabra adquiere soberanía y salta hacia fuera de la frase, la frase se extiende y oscurece el sentido de la página, la página cobra vida a expensas del todo - el todo no es ya un todo".

${ }^{21}$ Sobre la lectura de Nietzsche del libro de Bourget, véase M. Montinari, "Compiti della ricerca nietzscheana oggi”, en G. Campioni y A. Venturelli (eds.), La 'biblioteca ideale' di Nietzsche, Nápoles: Guida Editori, 1992, pp. 267-282. Montinari observa que, mientras que en los Essais de Bourget, el movimiento va de lo general a lo particular, en El Caso Wagner de Nietzsche va de lo particular a lo general, de la palabra al libro (pp.280-281). Giuliano Campioni lleva adelante la investigación en su obra Lectures françaises de Nietzsche. Trad. Christel Lavigne-Mouilleron, Paris: PUF, 2001, en particular en el capítulo titulado "Le voyage à Cosmopolis de Monsieur Nietzsche" (pp. 229-260); en portugués, Nietzsche e o espírito latino, São Paulo: Loyola, 2016, pp. 291-326. Realizando un trabajo sobre la literatura francesa de la época y las apropiaciones que Nietzsche hace de ella, Campioni muestra que, en los fragmentos póstumos de la primavera-verano de 1883-1884, el filósofo define, a partir de la lectura de los Essais de Bourget, las categorías de su interpretación fisiológica de Wagner y del arte de la décadence, que se expresan sistemáticamente en El Caso Wagner.

${ }^{22}$ El Anticristo $\S 6, K S A$ 6.172. Cf. también Ecce Homo, "Por qué soy un destino", § 7, KSA 6.372: “Estará la humanidad misma en décadence? ¿Lo ha estado siempre? - Lo cierto es que a la humanidad no se le han enseñado otros valores supremos que los valores de la décadence”. 
sólo en el dominio moral. En el prólogo de El Caso Wagner, subraya que "la diferenciación entre 'bueno y malvado' no es sino una variedad" del problema de la décadence ${ }^{23}$. Si Nietzsche critica el cristianismo desde un punto de vista moral, también lo combate en cuanto religión: el Dios cristiano, esta "contradicción de la vida", es un "híbrido producto de la décadence"24. Si bien aprecia el budismo, porque sería más realista que el cristianismo, no se priva, sin embargo, de atacarlo, afirmando que el budismo y el cristianismo, "ambos, como religiones nihilistas, pertenecen al mismo conjunto unitario son religiones de décadence"25.

En el campo de la filosofía, Nietzsche critica el imperativo categórico de Kant que, imponiendo la ley de la reciprocidad al individuo y llevándole a actuar "como un autómata del 'deber"", es "precisamente la receta que lleva a la decadencia"26. También lucha contra Schopenhauer, quien, privilegiando la compasión, habría instituido "un instrumento capital para el aumento de la décadence"27. Pero no es sólo en el pensamiento kantiano y en la filosofía schopenhaueriana donde se manifiesta la décadence. Nietzsche estima que ya está presente en los griegos. Llevando adelante su trabajo de idealización hasta el punto de inventar un mundo esencial, inmutable y eterno en oposición al mundo en que nos encontramos aquí y ahora, Platón sería responsable de hacer de la filosofía griega "la décadence del instinto griego"28. Sócrates, a su vez, por medio de la "superfetación de lo lógico", esta expresión de la décadence, conduciría a una expansión anormal de la razón y, por tanto, al debilitamiento de los impulsos ${ }^{29}$.

Nada escapa al ojo crítico de Nietzsche. En Crepúsculo de los ídolos, caracteriza "la democracia moderna y todas sus variedades insuficientes, así el 'Reich alemán', como forma de la decadencia del Estado". Considera que el concepto moderno de libertad es "un síntoma de décadence" y define el progreso moderno teniendo "como meta el que todas las cosas vayan como los cangrejos": "ir avanzando paso a paso en la décadence" 30 . Afirma que su objeción "contra toda la sociología en Inglaterra y Francia sigue siendo que no conoce por experiencia sino los productos del declive de la sociedad" 31 .

${ }^{23}$ Cf. El Caso Wagner, "Prólogo", KSA 6.11.

${ }^{24}$ Cf. respectivamente El Anticristo $\S 18, K S A$ 6.185, y $\S 19$, KSA 6.185. Véase también Ecce Homo, "Genealogía de la Moral", $K S A$ 6.353, en el que Nietzsche considera el ideal ascético como "un ideal de décadence".

${ }_{25}$ El Anticristo $\S 20, K S A$ 6.186. Véase también El Anticristo $\S 42, K S A$ 6.215; El Caso Wagner, "Post-Scriptum", KSA 6.43.

${ }^{26}$ Cf. El Anticristo $\$ 11, K S A 6.177$.

${ }^{27}$ Cf. El Anticristo $\S 7$, KSA 6.173. Véase también El Caso Wagner $\S 4, K S A 6.21$ y Crepúsculo de los Ídolos, "Incursiones de un intempestivo", $\S 37, K S A$ 6.136s.

${ }^{28}$ Cf. Crepúsculo de los Ídolos, "Lo que tengo que agradecer a los antiguos", § 2, KSA 6.155s.

${ }^{29}$ Cf. Crepúsculo de los Ídolos, "El problema de Sócrates", § 4, KSA 6.69.

${ }^{30}$ Cf. respectivamente Crepúsculo de los idolos, "Incursiones de un intempestivo", § 39, KSA 6.141; Crepúsculo de los Ídolos, "Incursiones de un intempestivo", § 41, KSA 6.143; Crepúsculo de los Ídolos, "Incursiones de un intempestivo", § 43, KSA 6.144.

31 Crepúsculo de los ídolos, "Incursiones de un intempestivo", § 37, KSA 6.138. 
Al diagnosticar todas las formas de expresión de la décadence, Nietzsche la encontrará en la moral, la religión, la filosofía, la política, la sociología, el arte, la música, la literatura ${ }^{32}$. Al procurar contextualizarla, como Bourget, la asocia con el gran malestar que cursa en su época. Estimando que la décadence es una tendencia hostil a la vida, Nietzsche la detecta en todo un período histórico y en todo un continente, poniendo en evidencia su presencia en el siglo XIX en Europa ${ }^{33}$.

Décadent, la modernidad ignora los antagonismos y se desliza hacia una especie de ambigüedad en relación a la escala de valores. Es lo que le permite promover la idea de igualdad. Respecto a los estilos de la décadence, Nietzsche afirma:

En cada momento hay anarquía de los átomos, disgregación de la voluntad - si lo decimos moralmente, hay "libertad del individuo" - si lo ampliamos a una teoría política, "los mismos derechos para todos" ${ }^{34}$.

Al predicar la igualdad de derechos, la tendencia democrática no es más que una manifestación de décadence característica de la modernidad.

Queda por dilucidar cómo concibe Nietzsche la idea de igualdad. Es cierto que se aplica a combatirla en varios frentes. En el ensayo Sobre verdad y mentira en el sentido extramoral, muestra que las palabras, cuando pasan a servir para innumerables experiencias análogas a aquélla que les dio origen, se convierten en conceptos. "Igualando lo no-igual", y conjuntando varios fenómenos, los conceptos resultan inadecuados e insuficientes para cada uno de ellos en particular ${ }^{35}$. En La gaya ciencia procura mostrar que en los cimientos mismos en los que se basa la lógica está presente la tendencia ilógica a tratar a lo semejante como igual ${ }^{36}$. En Más allá del bien y del mal, insiste en que los mecanicistas, defendiendo la existencia de leyes en la naturaleza, no hacen

${ }^{32}$ Cf. El Caso Wagner $\$ 7, K S A$ 6.28, donde Nietzsche afirma que los hermanos Goncourt "tendrían puntos en común con el estilo de Wagner", y El Anticristo $\S 7, K S A 6.174$, donde se expresa sobre la décadence literaria y artística, refiriéndose a Tolstoi y Wagner. En varios pasajes, Nietzsche afirma que Wagner es el artista de la décadence. Véase por ejemplo El Caso Wagner $\S 4$ y $\$ 5, K S A 6.21$, "Segundo Postscriptum", KSA 6.46; El Anticristo \& 7, KSA 6.174.

${ }^{33} \mathrm{Cf}$. respectivamente Crepúsculo de los ídolos, "Incursiones de un intempestivo", §50, KSA 6.152 y El Caso Wagner $\S 5, K S A 6.22$.

${ }^{34}$ El Caso Wagner $\S 7, K S A$ 6.27. Nietzsche sigue diciendo: "La vida, la misma vitalidad, la vibración y exuberancia de la vida, comprimidas en las configuraciones mínimas, el resto es pobre en vida".

${ }^{35}$ Cf. Sobre Verdad y Mentira en sentido extramoral $§ 1, K S A 1.879$ s, donde leemos: "Toda palabra se convierte de manera inmediata en concepto cuando deja de servirle a la vivencia originaria, única y por completo individualizada, gracias a la cual se generó, por ejemplo, como recuerdo, y tiene que pasar a adaptarse a innumerables vivencias más o menos similares, esto es, hablando con rigor, nunca idénticas; es decir, tiene que valer al mismo tiempo para casos claramente diferentes".

${ }^{36}$ Cf. La gaya Ciencia $\S 111, K S A$ 3.471s: "La tendencia predominante a tratar a lo similar como igual, una tendencia ilógica -pues en sí no hay nada igual-, ha sido la que creado todos los fundamentos de la lógica". 
más que inclinarse ante el impulso democrático de los tiempos modernos. Y concluye: "En todos lados, igualdad ante la ley, — en eso la naturaleza no lo tiene ni distinto ni mejor que nosotros': gentil reticencia en la que de nuevo se enmascara la enemistad plebeya contra todo lo privilegiado y soberano" 37 . Por tanto, al investigar el proceso de formación de los conceptos, al examinar la base de los procedimientos lógicos, al analizar la actitud de los hombres de ciencia, encuentra ocasiones propicias para atacar la idea de igualdad.

Pero, ya sea anunciada por las religiones o defendida por las corrientes políticas, la idea de igualdad se convierte, a juicio de Nietzsche, en una idea engañosa y astuta. Desde los tiempos más remotos, la noción de equilibrio de fuerzas ha regulado las relaciones humanas. Para preservar su existencia, los individuos más débiles buscaron asociarse. Viviendo gregariamente, esperaban enfrentarse a aquellos que, más fuertes que ellos, pudieran llegar a amenazarlos. Por otro lado, los adversarios -ya fueran individuos o grupos-, siempre que tuvieran fuerzas equivalentes, concertaban la paz y establecieron contratos entre ellos. Así surgió la noción de ley. Reconociéndome derechos y permitiéndome preservarlos, cada miembro del grupo se comporta con prudencia, porque me toma como aliado frente a una tercera fuerza que nos amenaza; con miedo, ya que tiene recelo, en tanto teme confrontarse conmigo; con astucia, ya que espera, a cambio, que yo reconozca sus derechos y le permita preservarlos.

Los derechos mantienen relaciones de poder; constituyen "grados de poder". Nietzsche considera que "la no igualdad de derechos es la primera condición para que haya derechos en absoluto. - Un derecho es un privilegio" 38 . Mis derechos son esa parte de mi poder que otros reconocen y que me permiten conservar; mis deberes, los derechos que los otros tienen sobre mí. De ello se deduce que los derechos duran tanto como el equilibrio de fuerzas que los originó. Tan pronto como la fuerza de un cierto número de individuos se reduce considerablemente, los demás miembros del grupo dejan de reconocer sus derechos. Pero si, por el contrario, aumenta su fuerza, son ellos los que ya no garantizan los derechos de los demás. A medida que el equilibrio de fuerzas sufre cambios profundos, ciertos derechos desaparecen y otros emergen. Desde esta perspectiva, la igualdad de los ciudadanos ante la ley, un eco de la igualdad de los hombres ante Dios, no sería más que una fórmula forjada por quienes necesitan unir sus fuerzas para sobrevivir. Para preservar su propia existencia, el individuo más débil busca asociarse. Viviendo gregariamente, espera enfrentarse a quienes, más fuertes que él, puedan llegar a amenazarlo. Precisamente por eso instituye formas de actuar y de pensar universalmente válidas, censura toda originalidad, desaprueba todo cambio. Promotor de la vida colectiva, si intentara vivir de otra manera, sucumbiría. "Animal de rebaño",

${ }^{37}$ Más allá del Bien y del Mal § 22, KSA 5.37.

${ }^{38}$ El Anticristo § 57, KSA 6.243.

Araucaria. Revista Iberoamericana de Filosofia, Politica, Humanidades y Relaciones Internacionales, año $23, \mathrm{n}^{\circ} 46$. Primer cuatrimestre de 2021. Pp. 307-325. ISSN 1575-6823 e-ISSN 2340-2199 https://dx.doi.org/10.12795/araucaria.2021.i46.15 
exige continuamente la victoria de cada uno sobre sí mismo. Considerando quién reina en la Europa de su tiempo, Nietzsche no duda en decir:

\begin{abstract}
¡La doctrina de la igualdad!... Pero no hay ningún veneno más venenoso: pues parece predicada por la justicia misma, cuando es el final de la justicia... "Igualdad para los iguales, desigualdad para los desiguales" - esto sería el verdadero discurso de la justicia: y, lo que de ello se sigue, no igualar nunca lo que es desigual ${ }^{39}$.
\end{abstract}

A juicio del filósofo, en los tiempos modernos, la idea de igualdad ha pasado a ser concebida como sinónimo de nivelación gregaria. Convirtiéndola en uno de sus blancos privilegiados, convierte sus ataques a esta idea en el núcleo argumentativo de la crítica que dirige a la modernidad.

Es sobre todo la idea de igualdad asociada a la corriente democrática de los tiempos modernos lo que Nietzsche combate ${ }^{40}$. Así que no es por casualidad el que se vuelva contra Rousseau. Predicando la igualdad, el autor de El contrato social pretende volver a un estado primitivo, natural y puro. De hecho, su manera de pensar estaría errada desde la base; Rousseau se habría equivocado en la relación de causa y efecto que estableció entre civilización y moralidad. Desde la perspectiva nietzscheana, nuestra civilización no es responsable de nuestra mala moralidad; por el contrario, "lo bueno de nuestra moralidad" es responsable de "lo deplorable de esta civilización"41. Al asociar a Rousseau con la Revolución francesa, Nietzsche no duda en tomarlo como uno de "los que no puedo soportar" 42 . En Crepúsculo de los ídolos, afirma:

\begin{abstract}
La farce [farsa] sangrienta con la que se representó esa Revolución, su "inmoralidad", me importan poco: lo que yo odio es su moralidad rousseauniana - las pretendidas “verdades" de la Revolución, con las que esta continúa teniendo efecto y persuadiendo en su favor todo lo que es superficial y mediocre ${ }^{43}$.
\end{abstract}

${ }^{39}$ Crepúsculo de los Ídolos, "Incursiones de un intempestivo", § 48, KSA 6.150. Véase también Más allá del Bien y del Mal § 212, KSA 5.147, donde leemos: "La 'igualdad de derechos' podría transformarse fácilmente en la igualdad dentro de la injusticia: quiero decir, en un combate generalizado contra todo lo singular, extraño, privilegiado, contra el hombre superior, el alma superior, el deber superior, la responsabilidad superior, contra la plenitud de poder y el dominio creativos".

40 Véase D. Sánchez Meca, Nietzsche, la experiencia dionisíaca del mundo, Madrid: Tecnos, $4^{\mathrm{a}}$ ed., 2009, en particular pp. 181-220. En la página 193, el autor escribe: "La reivindicación de derechos iguales es antiaristocrática".

${ }^{41}$ Aurora $\S 163$, KSA 3.146. El párrafo se titula "Contra Rousseau".

${ }^{42}$ Cf. Crepúsculo de los Ídolos, "Incursiones de un intempestivo", § 1, KSA 6.111: "Rousseau: o el retorno a la naturaleza in impuris naturalibus".

${ }^{43}$ Crepúsculo de los Ídolos, "Incursiones de un intempestivo", § 48, KSA 6.150. Sobre este tema, cf. U. Marti, "Der grosse Pöbel- und Sklavenaufstand”. Nietzsches Auseinandersetzung mit Revolution und Demokratie, Stuttgart: Metzler, 1993, en particular los capítulos titulados „Nietzsches Urteil über die Französische Revolution“ y „Rousseau, Kant und die Moralität der Revolution“. 
Intentando imponer lo que es uniforme, la moralidad rousseauniana, que en cierta medida habría provocado ese acontecimiento histórico, consistiría sobre todo en una determinada concepción de la igualdad: la que suprime las diferencias y excluye las excepciones ${ }^{44}$. Al defenderla, Rousseau habría contribuido de manera decisiva a la Revolución Francesa. Pero igualmente habría contaminado con sus ideas la filosofía de Kant. Refiriéndose al "chino de Koenigsberg" en el prólogo de Aurora, Nietzsche afirma:

También a él había picado la tarántula de la moral que fue Rousseau, también él tenía en el fondo del alma la idea del fanatismo moral, del cual otro discípulo de Rousseau, a saber, Robespierre, se sentía y se reconocía ejecutor ${ }^{45}$.

Del examen de este texto se desprenden dos cuestiones. En primer lugar, nótese que las huellas dejadas por el pensamiento de Rousseau en la filosofía de Kant no escapan a Nietzsche. Si no se muestra innovador al apuntar este hecho, un lugar común para la mayoría de los comentaristas, revela su originalidad al juzgarlo. Kant y también Robespierre, en su condición de discípulos del pensador ginebrino, habrían heredado su fanatismo moral. Y el fanatismo, presente, por cierto, también en Lutero y en todos los espíritus limitados, traduciría la defensa de convicciones profundamente arraigadas, impidiendo el descubrimiento de nuevas ideas. En este sentido afirma Nietzsche: "La patológica condicionalidad de su óptica hace del convencido un fanático -Savonarola, Lutero, Rousseau, Robespierre, Saint-Simon- el tipo en antítesis del espíritu fuerte, del espíritu que ha llegado a ser libre" ${ }^{" 46}$. Por otro lado, el pasaje del prólogo a Aurora mencionado anteriormente permite ver que Nietzsche está atento a las preocupaciones morales que se extienden por la obra de Rousseau. Araña que se enreda en su tela, causa fiebre y provoca delirios, el ciudadano de Ginebra habría impreso su huella en el siglo XVIII. Y así se caracterizaría el período histórico en el que vivió: "Feminismo - Rousseau, dominio del sentimiento, testimonio de la soberanía de los sentidos (falaz)" $"$.

En el contexto del pensamiento nietzscheano, la figura de Rousseau sólo adquiere sus contornos más precisos cuando se contrapone a la de Voltaire. Un pasaje de Humano, demasiado humano nos permite comprender que Voltaire encarna precisamente la antítesis de Rousseau.

${ }^{44}$ A este respecto, Urs Marti sostiene: "Por moralidad, Nietzsche entiende en primer lugar la doctrina de la igualdad, que, en su opinión, seduce a los espíritus mediocres y mina la creencia en la jerarquía" ("Nietzsches Kritik der Französischen Revolution", en Nietzsche-Studien 19 (1990), pp. 312-335, aquí p.313). Siguiendo de cerca a Urs Marti, Ansell-Pearson afirma: "Él [Nietzsche] asocia a Rousseau con lo que él llama la 'moralidad' de la Revolución, es decir, la doctrina de la igualdad" (Nietzsche contra Rousseau. A Study of Nietzsche's Moral and Political Thought, Cambridge: University Press, 1992, p. 32).

${ }^{45}$ Aurora, "Prólogo", § 3, KSA 3.14.

${ }^{46}$ El Anticristo § 54, KSA 6.237.

47 Fragmento póstumo (128) 9 [178] otoño de 1887, KSA 12.440. A este respecto, véase también Aurora $§ 17$, KSA 3.29s, y Fragmento póstumo (87) 9 [131] otoño de 1887, KSA 12.412.

Araucaria. Revista Iberoamericana de Filosofia, Politica, Humanidades y Relaciones Internacionales, año $23, \mathrm{n}^{\circ} 46$. Primer cuatrimestre de 2021. Pp. 307-325. ISSN 1575-6823 e-ISSN 2340-2199 https://dx.doi.org/10.12795/araucaria.2021.i46.15 
No la naturaleza mesurada de Voltaire, tendente a ordenar, depurar y reconstruir, sino las locuras apasionadas y medias verdades de Rousseau suscitaron el espíritu optimista de la revolución francesa; contra él quiero gritar "Écrasez l'infâme!"48.

Por un lado, las Luces; por otro, la Revolución Francesa. Por un lado, el aristocratismo; por otro, la plebe ${ }^{49}$. Al lanzar contra Rousseau la frase de Voltaire, el autor de Humano, demasiado humano revela sus preferencias. El autor de este libro "para espíritus libres", "consagrado a la memoria de Voltaire con motivo de la celebración del aniversario de su muerte el 30 de mayo de 1778 ", reafirma sus predilecciones.

Que Nietzsche asume la defensa del aristocratismo frente al ideal gregario, resulta evidente al repasar sus textos ${ }^{50}$. Sin embargo, la aristocracia de la que habla no es sólo el fruto de una elaboración teórica; él supone hallarla en diferentes épocas históricas. El hombre noble al que se refiere no se reduce a un mero concepto; cree encontrarlo en contextos muy precisos. Considera que existió en los siglos XVII y XVIII con la nobleza francesa, en el Renacimiento con la comunidad aristocrática de Venecia y sobre todo en la Antigua Grecia con la aristocracia guerrera ${ }^{51}$. Al remitirse a estudios históricos, el filósofo, sin duda, toma partido por un determinado tipo de organización social. Pero no es simplemente por eso por lo que recurre a la historia, sino para enriquecer su crítica de los valores. A su juicio, el trabajo del historiador contribuye a denunciar las reglas de conducta que aparecen como absolutamente necesarias, indicando el momento de su producción; concurre para atacar los juicios que pretenden ser universalmente válidos, mostrando las circunstancias de su

48 Humano, demasiado Humano § 463, KSA 2.299.

${ }^{49}$ En esta dirección, cf. G. Campioni, Op. Cit., donde leemos: “A estas 'Luces' caracterizadas por la figura de Voltaire, Nietzsche opone firmemente, desde Humano, demasiado Humano, la figura de Rousseau que representa la corrupción del espíritu de las Luces en una dirección 'fanática' y moral: el primero es tan aristocrático y serenamente 'libre', campeón de la tolerancia, cuanto el segundo es ‘plebeyo’ y podrido de sentimentalismo, intolerante, expresión de debilidad romántica” (p. 47).

50 Es la posición que también defiende Bruce Detwiler. Al final de su libro, afirma: "Es difícil pensar en otro autor moderno de la talla de Nietzsche, cuya orientación política sea al mismo tiempo tan aristocrática y radical como la suya. Entre los filósofos modernos, Nietzsche sigue siendo prácticamente el único que insiste en que el objetivo de la sociedad debe ser la promoción y elevación del tipo superior, incluso a expensas de lo que tradicionalmente se ha pensado que es bueno para todos o para la mayoría (Nietzsche and the Politics of Aristocratic Radicalism, Chicago: University of Chicago Press, 1990, p. 189). Entre numerosos pasajes, véase en esa dirección Fragmento póstumo (371) 11 (140) noviembre de 1887-marzo de 1888, KSA 13.65. Cabe recordar también que, entusiasmado con la Genealogía de la Moral, que le había enviado Nietzsche, Georg Brandes decidió difundir su pensamiento. Además de pronunciar una serie de conferencias sobre su filosofía en la Universidad de Copenhague en febrero de 1888, escribió una reseña del libro, al que llamó "Radicalismo aristocrático". Véase G. Brandes, "Aristokratischer Radikalismus", en A. Guzzoni (hrsg.), 90 Jahre philosophische Nietzsche-Rezeption, Königstein: Verlag Anton Hain Meisenheim, 1979, pp. 1-15. Parece que fue muy apreciada por el filósofo en su publicación.

${ }^{51}$ Cf. respectivamente Genealogía de la Moral, "Primer Tratado", § 16, KSA 5.285s; Crepúsculo de los Ídolos, "Incursiones de un intempestivo", § 38, KSA 6.139s; Aurora § 199, KSA 3.173s. 
aparición; colabora, en fin, para desenmascarar las generalizaciones indebidas, enfatizando la especificidad de cada caso. Es, sobre todo, fundamental en la crítica de los ideales, en cuanto constituye un arma eficaz de combate contra cualquier impulso metafísico.

Además de la contribución decisiva de la investigación histórica, Nietzsche se apoya en el concurso de filología. En el prefacio de La genealogía de la moral, sugiere que "cierta formación histórica y filológica, a más de un sentido innato difícil de contentar en lo que toca a cuestiones psicológicas" ${ }^{52}$ le ayudó a instaurar el procedimiento genealógico y a elaborar la crítica de los valores. Cuando examina el cristianismo, ciertamente recurre a la filología; al dedicarse al análisis de la moral de los resentidos, sin duda hace uso de la historia. No cabe aquí, sin embargo, hacer una valoración de los usos (o apropiaciones) que hace de los datos filológicos o de los elementos históricos, sino sólo subrayar su propósito de emplearlos en sus reflexiones sobre la procedencia y las transformaciones por las que atraviesan los valores. Armado de esos elementos, se aplica a reflexionar sobre doctrinas morales, acontecimientos políticos y enseñanzas religiosas. Con esos datos en la mano, se dedica a examinar la tendencia democrática de la modernidad.

Es en cuanto psicólogo como Nietzsche afronta el ideario moderno; pretende diagnosticar los móviles ocultos de quienes lo apoyan. Y es en calidad de genealogista como lo evalúa; quiere juzgar los valores inconfesados de quienes lo defienden ${ }^{53}$. En su opinión, las "ideas modernas" se imponen en detrimento de todo orden jerárquico. Es lo que le lleva a denunciar la obra del cristianismo y el proceder de los resentimientos en ellos. Tanto es así que asegura en La gaya ciencia:

Sólo la Revolución Francesa ha entregado completa y solemnemente el cetro al "buen hombre" (al cordero, al asno, al ganso y a todo lo que es incurablemente plano y vocinglero y está maduro para el manicomio de las "ideas modernas") ${ }^{54}$.

Pero ya es hora de preguntarse: ¿cómo concebir la idea misma de igualdad? ¿Y cuáles son sus implicaciones? Por tanto, es importante investigar qué se entiende por justicia.

Sabemos que, en la modernidad, justicia puede significar seis tipos de afirmaciones: a cada uno lo mismo; a cada uno según sus méritos; a cada uno

${ }^{52}$ Genealogía de la Moral, "Prólogo", § 3, KSA 5.249.

${ }_{53}$ No podemos seguir a Simone Goyard-Fabre cuando afirma, refiriéndose a la Revolución Francesa: "Es esencialmente como metafísico como Nietzsche -al igual que Hegel en este punto considera y juzga el acontecimiento revolucionario" (Nietzsche et la question politique, Paris: Sirey, 1977, p. 99).

${ }^{54}$ La gaya Ciencia $\S 350, K S A$ 3.586. Respecto la crítica de Nietzsche a esta divisa revolucionaria, véase S. Marton, "Nietzsche et la Révolution Française. Remarques sur la divise révolutionnaire", en C. Denat y C. Piazzesi (eds.), Nietzsche, penseur de la politique? Nietzsche, penseur du social? Pisa: Edizioni ETS, 2011, pp. 119-132. 
según sus obras;a cada uno según sus necesidades; a cada uno según su lugar, clase, estatus; a cada uno según lo que le asigne la ley, pudiéndose entenderse la ley formalmente o como algo que tiene desde siempre un contenido. Aunque estas definiciones son incompatibles entre sí, tienen algo en común; en ellas hay un principio de acción, según el cual seres de una misma categoría esencial deben ser tratados de la misma manera. Sin embargo, ninguna de estas definiciones ni su denominador formal hace más que fijar límites dentro de los cuales se puede discutir el concepto de justicia, un concepto que requiere tanto una formalización cuanto una referencia constante a bases históricas.

Es importante señalar aquí que el principio de acción común a todas estas definiciones se basa en una idea central: la de igualdad. Es cierto que se puede hablar de igualdad en diferentes registros: igualdad matemática, igualdad geométrica, igualdad lógica, igualdad formal, igualdad material, igualdad política, igualdad jurídica. En la Declaración de Derechos Humanos, por ejemplo, el artículo primero define: "todos los hombres nacen y permanecen libres e iguales en derechos". Esta afirmación reviste la forma de una aseveración de facto, que se refiere a la naturaleza de las cosas. Pero no designa algo real, sino un ideal que no se realiza en ninguna sociedad; sólo apunta, pues, a la igualdad formal de derechos. Por lo tanto, cuando se habla de igualdad, el término debe emplearse determinando de modo preciso las ideas a las que se le quiere asociar. Además, es necesario distinguir con precisión, por un lado, el ideal que se quiere alcanzar y, por otro, la situación que realmente existe; por un lado, la igualdad formal, que consiste en los derechos de los individuos, en las reglas según las cuales son tratados, y, por otro, la igualdad material, que consiste en lo que son de facto, tanto desde el punto de vista de su situación material como de su condición personal.

La investigación en el campo de la biología y la psicología muestra bien que los individuos difieren en sus configuraciones genéticas y disposiciones afectivas. La afirmación de que todos los seres humanos son iguales no puede basarse en la posesión de inteligencia, razón, ciertas propensiones emocionales, cierta tendencia moral o cualquier dato de ese tipo. En suma, no existe una base fáctica para el principio de igualdad. De donde se podría concluir que, lejos de referirse a un enunciado fáctico, la idea de igualdad se presenta como un principio ético básico ${ }^{55}$. Nietzsche estaría sin duda de acuerdo con esa afirmación. La idea de que la igualdad no es una aseveración fáctica contaría con su adhesión; de hecho, no son pocos los pasajes en los que argumenta en ese sentido. También la idea de que la igualdad es un principio ético básico también contaría con su asentimiento; en este caso, se esforzaría en mostrar que este principio se halla a la base de una determinada moral: la cristiana. Tanto es

${ }^{55}$ Véase em esta dirección, por ejemplo, P. Singer, Practical Ethics, Cambridge: University Press, $3^{\text {rd }}$ ed., 2011.

Araucaria. Revista Iberoamericana de Filosofía, Política, Humanidades y Relaciones Internacionales, año $23, \mathrm{n}^{\circ} 46$. Primer cuatrimestre de 2021. Pp. 307-325. ISSN 1575-6823 e-ISSN 2340-2199 https://dx.doi.org/10.12795/araucaria.2021.i46.15 
así que, en Más allá del bien y del mal, no duda en afirmar que "el movimiento democrático constituye la herencia del movimiento cristiano" 56.

Pero es sobre todo tomada como un ideal que jamás se realiza como la idea de igualdad podría atraer la atención de Nietzsche. En Ecce Homo, declara que “derribar idolos (mi palabra para 'ideales') -esto ya sí que forma parte de mi oficio" 57 . Desde la perspectiva nietzscheana, pensar en un ideal democrático presentaría, al menos, dos inconvenientes. En primer lugar, implicaría comprometerse con el pensamiento metafísico, expediente que emplean aquellos que son incapaces de aceptar esta condición humana nuestra $\mathrm{y}$, por eso mismo, rechazan este mundo en el que nos encontramos aquí y ahora en nombre de otro, que sería esencial, inmutable y eterno. Además, implicaría respaldar la idea de igualdad formal de los miembros de la sociedad, idea que supondría proceder a la nivelación gregaria y la uniformidad.

Ahora bien, nuestra sociedad se organiza precisamente en torno a la competencia, y ésta es tanto mayor cuanto más indeterminado es el campo de acción de las comparaciones, de modo que cada uno tiene derecho a juzgar que vale tanto como cualquier otro, pero no hay forma de tener el mismo valor. Así, la nivelación promovida por el consumo sólo profundiza la desigualdad, ya que la supuesta igualdad social convive con diferencias considerables de hecho, en términos de poder, riqueza y cultura. De ello se deduce que, a medida que la igualdad formal de derechos se convierte en la estandarización del consumidor, el resentimiento alcanza su clímax.

No cabe duda de que, entre los descubrimientos filosóficos más importantes de los últimos ciento treinta años, se encuentra el fenómeno del resentimiento. Al investigar cómo se instituyeron los valores morales, Nietzsche diagnosticó lúcidamente, por primera vez, la forma de pensar, actuar y sentir de los resentidos. Incapaz de reaccionar, el individuo se vuelve resentido y busca venganza. No pudiendo igualarse a su agresor, se siente impotente y, en consecuencia, se resiente. Pero la envidia, los celos y la ira también son fuentes de resentimiento. Cuando se siente disgustado por no tener lo que tiene el otro, el individuo se esfuerza por conseguir lo que desea. Al no tener éxito en sus esfuerzos, se siente impotente y, entonces, se resiente. Siempre es de una cierta disposición a compararse con el otro de donde nace el resentimiento.

Aplicando estas ideas a las relaciones sociales, sería posible sostener que cuanto mayor sea la distancia entre el estatus legal de los diferentes grupos sociales, condición dada por el sistema político o la tradición, y su poder real, mayor será el resentimiento ${ }^{58}$. En un sistema social claramente diferenciado o en una sociedad de castas como por ejemplo la India, el resentimiento

\footnotetext{
56 Más allá del Bien y del Mal § 202, KSA 5.125.

57 Ecce Homo, "Prólogo", § 2, KSA 6.258.

${ }^{58}$ Véase M. Scheler, Das Ressentiment im Aufbau der Moralen, Frankfurt: Klostermann, 2. Aufl., 2004.
}

Araucaria. Revista Iberoamericana de Filosofía, Política, Humanidades y Relaciones Internacionales, año $23, \mathrm{n}^{\circ} 46$. Primer cuatrimestre de 2021. Pp. 307-325. ISSN 1575-6823 e-ISSN 2340-2199 https://dx.doi.org/10.12795/araucaria.2021.i46.15 
sería pequeño. Y, de igual modo, en una democracia que, tanto social como políticamente, tendiese a la igualdad de riquezas. Llevando este razonamiento a sus últimas consecuencias, no se puede evitar la conclusión de que, al fomentar la diferencia de estatus, nuestra sociedad promueve -y genera en todo momento- el resentimiento.

Es cierto que el pensamiento nietzscheano puede ser de gran valor para reflexionar sobre esas cuestiones. Revela su carácter innovador cuando se trata de criticar la cultura. En este contexto, es como imposición de lo uniforme, de lo gregario, como Nietzsche ve la igualdad. Sin embargo, al hacer de la política objeto de la crítica de los valores, tiende a subrayar que los efectos nocivos del movimiento democrático no se restringirían al ámbito político stricto sensu; se verían en la cultura en general. En ese sentido, el filósofo pregunta en un pasaje de Más allá del bien y del mal:

\begin{abstract}
Nosotros, que tenemos otra fe, nosotros, que consideramos el movimiento democrático no sólo como una forma decadente de organización política, sino como una forma de decadencia, es decir, de empequeñecimiento del ser humano, como su mediocrización y su reducción de valor: ¿hacia dónde tenemos que dirigir nosotros nuestras esperanzas? ${ }^{95}$.
\end{abstract}

De esta forma tan inusual en nuestros días se posiciona en relación a la democracia; y de esta manera polémica es como la trata.

El examen de diversos pasajes en los que Nietzsche se ocupa de la tendencia democrática de la modernidad nos lleva a juzgar ambivalente la posición que adopta. Si en el ámbito de la crítica de la cultura se muestra innovador, es cierto que, en sus ataques a la tendencia democrática de los tiempos modernos, toma la defensa del aristocratismo. Es importante resaltar aquí que, si bien cree que no pueden ser ignoradas las consecuencias en el dominio cultural de la idea de igualdad, entendida como una nivelación y estandarización gregarias, anticipándose así a la crítica que vino a desarrollarse posteriormente a lo que se denominó industria cultural, Nietzsche asume posiciones con consecuencias políticas difícilmente defendibles hoy en día.

[Traducción del portugués de Manuel Barrios Casares]

${ }^{59}$ Más allá del Bien y del Mal § 203, KSA 5.126.

Araucaria. Revista Iberoamericana de Filosofia, Política, Humanidades y Relaciones Internacionales, año $23, \mathrm{n}^{\circ} 46$. Primer cuatrimestre de 2021. Pp. 307-325. ISSN 1575-6823 e-ISSN 2340-2199 https://dx.doi.org/10.12795/araucaria.2021.i46.15 


\section{Referencias bibliográficas:}

Acampora, Christa D., "Demos Agonists Redux. Reflections of the Streit of Political Antagonism”, en Nietzsche-Studien 32 (2003), pp. 374-390.

Ansell-Pearson, Keith, An Introduction to Nietzsche as Political Thinker, Cambridge: University Press, 1994.

Ansell-Pearson, Keith, Nietzsche contra Rousseau. A Study of Nietzsche's Moral and Political Thought, Cambridge: University Press, 1992.

Appel, F., Nietzsche contra Democracy, Ithaca: Cornell University Press, 1999. Behler, Ernst, Ironie und literarische Moderne, Paderborn: Ferdinand Schöningh, 1997.

Behler, Ernst, Frühromantik, Berlin: de Gruyter, 1992.

Bergmann, P., Nietzsche. The "Last Anti-Political German”, Bloomington: Indiana University Press, 1987.

Bourget, Paul, Baudelaire y otros estudios críticos, trad. de S. Sánchez, Córdoba: Ediciones de Copista, 2008.

Bourget, Paul, Essais de psychologie contemporaine. Études littéraires, Paris: Gallimard, 1993.

Brandes, Georg, "Aristokratischer Radikalismus", en A. Guzzoni (hrsg.), 90 Jahre philosophische Nietzsche-Rezeption, Königstein: Verlag Anton Hain Meisenheim, 1979, pp. 1-15.

Brobjer, Thomas. H., "Nietzsche as Political Thinker. A Response to D. Dombowsky", en Nietzsche-Studien 30 (2001), pp. 394-396.

Brobjer, Thomas H., "The Absence of Political Ideals in Nietzsche's Writings", en Nietzsche-Studien 27 (1998), pp. 300-318.

Campioni, Giuliano, Nietzsche e o espírito latino. Trad. Vinicius de Andrade. São Paulo: Loyola, 2016.

Campioni, Giuliano, Lectures françaises de Nietzsche. Trad. Christel LavigneMouilleron, Paris: PUF, 2001.

Campioni, Giuliano et al. (eds.), Nietzsches persönliche Bibliothek, Berlin: de Gruyter, 2003.

Connoly, W., Political Theory and Modernity, Oxford: University Press, 1989. Conway, D., Nietzsche and the Political, Londres: Routledge, 1997.

Del Caro, Adrian, Nietzsche contra Nietzsche, Louisiana: State University Press, 1989.

Detwiler, Bruce, Nietzsche and the Politics of Aristocratic Radicalism, Chicago, University of Chicago Press, 1990.

Dombowsky, D., "A Response to Alan D. Schrift's 'Nietzsche for Democracy?'”, en Nietzsche-Studien 31 (2002), pp. 278-290. 
Dombowsky, D., “A Response to Thomas H. Brobjer's 'The Absence of Political Ideals in Nietzsche's Writings"”, en Nietzsche-Studien 30 (2001), pp. 387-393.

Goyard-Fabre, Simone, Nietzsche et la question politique, Paris: Sirey, 1977.

Hatab, L. J., A Nietzschean Defense of Democracy. An Experiment in Postmodern Politics, Chicago: Open Court, 1995.

Honig, B., Political Theory and the Displacement of Politics, Ithaca: Cornell University Press, 1993.

Kofman, Sarah, "Nietzsche et Wagner. Comment la musique devient bonne pour les cochons", en Furor 23 (Mai 1992), pp. 3-28.

Luque, Gloria, "Informe bibliográfico: Nietzsche y la política", in Estudios Nietzsche 15 (2015), pp. 157-163.

Marton, Scarlett, "Nietzsche et la Révolution Française. Remarques sur la divise révolutionnaire”, en C. Denat y C. Piazzesi (eds.), Nietzsche, penseur de la politique? Nietzsche, penseur du social? Pisa: Edizioni ETS, 2011, pp. 119-132.

Mc Intyre, A., The Sovereignty of Joy. Nietzsche's Vision of Grand Politics, Toronto: University Press, 1997.

Mc Intyre, A., "Virtuosos of Contempt': An Investigation of Nietzsche's Political Philosophy Through Certain Platonic Political Ideas", en Nietzsche-Studien 21 (1992), pp. 184-210.

Marti, Urs, "Der grosse Pöbel- und Sklavenaufstand”. Nietzsches Auseinandersetzung mit Revolution und Demokratie, Stuttgart: Metzler, 1993.

Marti, Urs, "Nietzsches Kritik der Französischen Revolution", en NietzscheStudien 19 (1990), pp. 312-335.

Montinari, Mazzino, "Compiti della ricerca nietzscheana oggi”, en G. Campioni y A. Venturelli (eds.), La 'biblioteca ideale’ di Nietzsche, Nápoles: Guida Editori, 1992, pp. 267-282.

Nietzsche, Obras completas (4 vols.), edición dirigida por Diego Sánchez Meca, Madrid: Editorial Tecnos, 2011-2016.

Nietzsche, Fragmentos póstumos (4 vols.), edición dirigida por Diego Sánchez Meca, Madrid: Editorial Tecnos, 2006-2010.

Ottmann, H., Philosophie und Politik bei Nietzsche, Berlin: de Gruyter, 1987.

Owen, David, Nietzsche, Politics and Modernity. A Critical of Liberal Reason, Londres: Thousand Oaks, 1995.

Pestalozzi, K., "Nietzsches Baudelaire-Rezeption", en Nietzsche-Studien 7 (1978), pp. 158-178.

Sánchez Meca, Diego, Nietzsche, la experiencia dionisíaca del mundo, Madrid: Tecnos, $4^{\text {a }}$ ed., 2009. 
Scheler, Max, Das Ressentiment im Aufbau der Moralen, Frankfurt: Klostermann, 2. Aufl., 2004.

Schrift, Alan D., "Response to Don Dombowsky", en Nietzsche-Studien 31 (2002), pp. 291-297.

Schrift, Alan D., "Nietzsche for Democracy?", en Nietzsche-Studien 29 (2000), pp. 220-232.

Sedgwick, P., "Violence, Economy and Temporality. Plotting the Political Terrain of On the Genealogy of Morality", en Nietzsche-Studien 34 (2005), pp. 163-185.

Siemens, Hermann, “Nietzsche's Political Philosophy: A Review of Recent Literature", en Nietzsche-Studien 30 (2001), pp. 508-526.

Singer, Peter, Practical Ethics, Cambridge: University Press, $3^{\text {rd }}$ ed., 2011.

Warren, M., Nietzsche and Political Thought, Cambridge, MIT Press, 1988. 
